\title{
A CASE OF REVERSIBLE QUADRIPARESIS - THYROTOXIC PERIODIC PARALYSIS
}

\author{
Santhosh Narayanan ${ }^{1}$, Thulaseedharan N. K2, Geetha P3, Danish E4
}

${ }^{1}$ Senior Resident, Department of Medicine, Government Medical College, Kozhikode.

2Professor and HOD, Department of Medicine and Endocrinology, Government Medical College, Kozhikode.

3 Professor, Department of Medicine and Endocrinology, Government Medical College, Kozhikode.

${ }^{4}$ Assistant Professor, Department of Medicine, Government Medical College, Kozhikode.

\section{ABSTRACT}

We describe a 38-year-old man who presented to the Emergency Department with an episode of weakness of both lower limbs followed by weakness of upper limbs of 6 hours' duration, which occurred after exertion. Physical and laboratory examination revealed sinus tachycardia, diffuse toxic goitre, flaccid quadriparesis. Investigations revealed a low serum potassium level and an undetectable TSH level. He was subsequently diagnosed with Grave's disease. Hypokalaemia was corrected with potassium supplements and antithyroid drugs were given and patient improved dramatically. On followup after 6 months, patient is asymptomatic and euthyroid.

\section{KEYWORDS}

Thyrotoxicosis, Hypokalaemia.

HOW TO CITE THIS ARTICLE: Narayanan S, Thulaseedharan NK, Geetha P, et al. A case of reversible quadriparesis - thyrotoxic periodic paralysis. J. Evolution Med. Dent. Sci. 2017;6(2):144-145, DOI: 10.14260/Jemds/2017/35

\section{BACKGROUND}

Thyrotoxic periodic paralysis is a rare disorder featured by thyrotoxicosis, hypokalaemia and flaccidity. It is one of the acquired form of periodic paralysis, next only to familial hypokalaemic periodic paralysis. The low plasma potassium levels are due to transcellular shift and is often precipitated by physical activity or ingestion of carbohydrates.

correction. He was initiated on antithyroid drug propylthiouracil in the dose of $200 \mathrm{mg}$. Betablockers were started to alleviate sympathetic symptoms. Hypokalaemia got corrected and ECG changes normalised. Patient regained his power of limbs and was able to move his limbs after 6 hours of treatment. Deep tendon reflexes became elicitable and he completely improved in a day. He is on regular medication and is euthyroid after 6 months of followup.
\end{abstract}

\section{CASE REPORT}

A 38-year-old man presented to our casualty because of weakness of lower limbs with difficulty in walking. He developed weakness of upper limbs after a few hours. He had h/o weight loss (about $10 \mathrm{~kg}$ ), fatigue, diarrhoea, heat intolerance, nervousness, insomnia and palpitation which appeared during the last few months. Physical examination revealed diffuse thyromegaly, mild exophthalmos without lid lag, absence of deep tendon reflexes in the upper and lower extremities, grade 0/5 motor power in his upper and lower extremities. Vital signs were as follows: blood pressure 90/60 $\mathrm{mmHg}$; heart rate $130 / \mathrm{min}$ regular; respiratory rate $40 / \mathrm{min}$ and body temperature $37^{\circ} \mathrm{C}$.

Investigations revealed serum potassium level of 1.5 $\mathrm{mmol} / \mathrm{L}$ (normal, 3.5 - $5.5 \mathrm{mmol} / \mathrm{L}$ ). Thyroid function tests were ordered suspecting TPP, which showed a serum T3 level of $2.30 \mathrm{ng} / \mathrm{mL}$ (normal, $0.846-2.02 \mathrm{ng} / \mathrm{mL}$ ), serum T4 level $20.78 \mathrm{ng} / \mathrm{dL}$ (normal 5.13 - $14.06 \mathrm{ng} / \mathrm{dL}$ ), serum Thyroid Stimulating Hormone (TSH) level of $0.005 \mu \mathrm{IU} / \mathrm{mL}$ (normal, $0.27-4.2 \mu \mathrm{IU} / \mathrm{mL}$ ). ECG showed sinus tachycardia with diffuse ST segment changes and presence of $U$ waves. Intravenous potassium supplements given followed by oral

Financial or Other, Competing Interest: None.

Submission 23-11-2016, Peer Review 24-12-2016,

Acceptance 30-12-2016, Published 05-01-2017.

Corresponding Author:

Santhosh Narayanan,

Senior Resident,

Department of Medicine,

Government Medical College, Kozhikode.

E-mail: drsanthosh4@gmail.com

DOI: $10.14260 /$ jemds $/ 2017 / 35$

\section{(c) $($ ) $\$$}

\section{Figure Showing Exophthalmos}

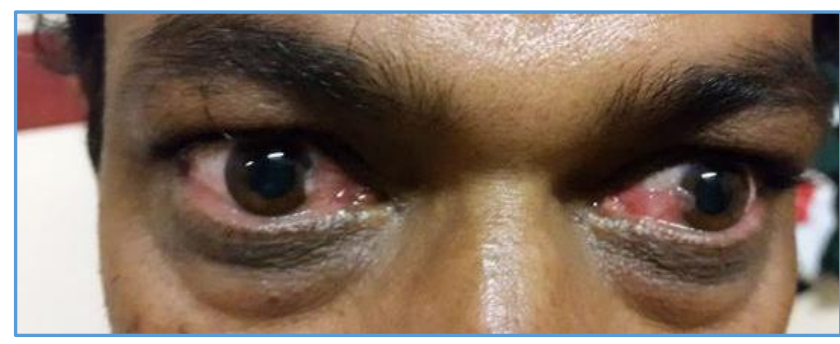

\section{DISCUSSION}

Thyrotoxic Periodic Paralysis (TPP) is rather under-reported in our population and is predominantly seen in males.[1] The usual age of onset of the disorder is similar to that of thyrotoxicosis, and is seen between second and fourth decades. Rarely, there is family history. There is a high incidence among Asians with association of HLA-DRw8.[2] The exact pathogenesis of TPP is yet to be elucidated, though it is postulated that it involves defects in membrane-bound iontransporting proteins such as sodium, K-adenosine triphosphatase or ion channel proteins.[3] TPP follows a heavy carbohydrate meal and this has been explained by hyperinsulinaemia which stimulates $\mathrm{Na}+\mathrm{K}(+)$-ATPase activity. The attacks of paralysis tend to occur during the night and after stress alcohol intake or a carbohydrate-rich meal, possibly due to hyperinsulinaemia. ${ }^{[4]}$ High dose glucocorticoids, antiretroviral therapy have also been identified as exacerbating factors. Total body potassium stores in TPP remains adequate, but potassium in the serum falls due to migration into sarcomeres which causes the muscles to become electrically unexcitable.[5] 
Diagnosis of TPP is based on clinical grounds and biochemical evidence of hyperthyroidism and hypokalaemia in a setting with a history of recurrent episodes of proximal muscle weakness involving mainly the lower limbs. Bulbar, ocular muscles and diaphragm are also sometimes affected. Cognitive and sensory function remains normal.

The immediate differential diagnosis of TPP is Familial Hypokalaemic Periodic Paralysis (FHPP). Both are similar in clinical presentation, but the latter has a strong family history. Mutations in the ionic channel genes such as CACNA1S, SCN4A and KCNE3 are reported in the FHPP, but not in TPP. Polymorphisms of the calcium channel alpha1subunit gene with TPP has been found in a few cases. The urine potassium-creatinine ratio and Transtubular Potassium Gradient (TTKG) are useful indices to diagnose hypokalaemia secondary to renal loss. Electrocardiographic changes found in TPP include sinus tachycardia due to the hyperadrenergic state, prolonged QT-U interval attributable to hypokalaemia, and a paradoxically prolonged PR interval due to the thyrotoxic state.[6] The Transtubular Potassium Gradient (TTKG) is a semiquantitative index of the activity of the potassium secretory process calculated as [urine $\mathrm{K} \div$ (urine osmolality/plasma osmolality) $] \div$ plasma K. Normal acid-base status and low urinary potassium excretion (urine potassium-creatinine ratio $<2$ and TTKG $<3$ ) are characteristics of hypokalaemia in TPP.[7]

Management of TPP consists of treatment of thyrotoxicosis by medical therapy, surgery or radioactive iodine therapy. Treatment for an acute attack is administration of potassium and beta-adrenergic blockade, but excessive doses of potassium will result in hyperkalaemia once potassium enters the extracellular space.[8] No correlation between potassium dose administered and recovery time has been established until now.

\section{CONCLUSION}

TPP should be taken into consideration in the differential diagnosis of all acute episodes of motor paralysis, especially in young patients. TPP is treated by cautious replacement of potassium and achievement of a euthyroid state. Early diagnosis is important to prevent morbidity and mortality.

\section{REFERENCES}

[1] Manoukian MA, Foote JA, Crapo LM. Clinical and metabolic features of thyrotoxic periodic paralysis in 24 episodes. Arch Intern Med 1999;159(6):601-6.

[2] Ahlawat SK, Sachdev A. Hypokalaemic paralysis. Postgrad Med J 1999;75(882):193-7.

[3] Magsino CH, Ryan AJ. Thyrotoxic periodic paralysis. South Med J 2000;93(10):996-1003.

[4] Seshadri P, Frank KD, Iqbal N. Thyrotoxic hypokalemic periodic paralysis in a native American patient: case report and literature review. Endocr Pract 2002;8(5):362-3.

[5] Lu KC, Hsu YJ, Chiu JS, et al. Effects of potassium supplementation on the recovery of thyrotoxic periodic paralysis. Am J Emerg Med 2004;22(7):544-7.

[6] Huang TY, Lin SH. Thyrotoxic hypokalemic periodic paralysis reversed by propranolol without rebound hyperkalemia. Ann Emerg Med 2001;37(4):415-6.

[7] Hsu Y, Lin Y, Chau T, et al. Electrocardiographic manifestations in patients with thyrotoxic periodic paralysis. Am J Med Sci 2003;326(3):128-32.

[8] Goldberger ZD. Images in cardiovascular medicine. An electrocardiogram triad in thyrotoxic hypokalemic periodic paralysis. Circulation 2007;115(6):e179-80. 